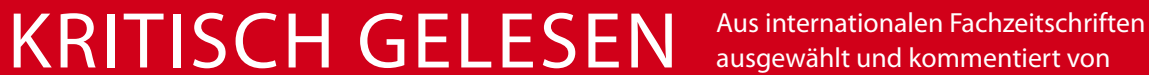

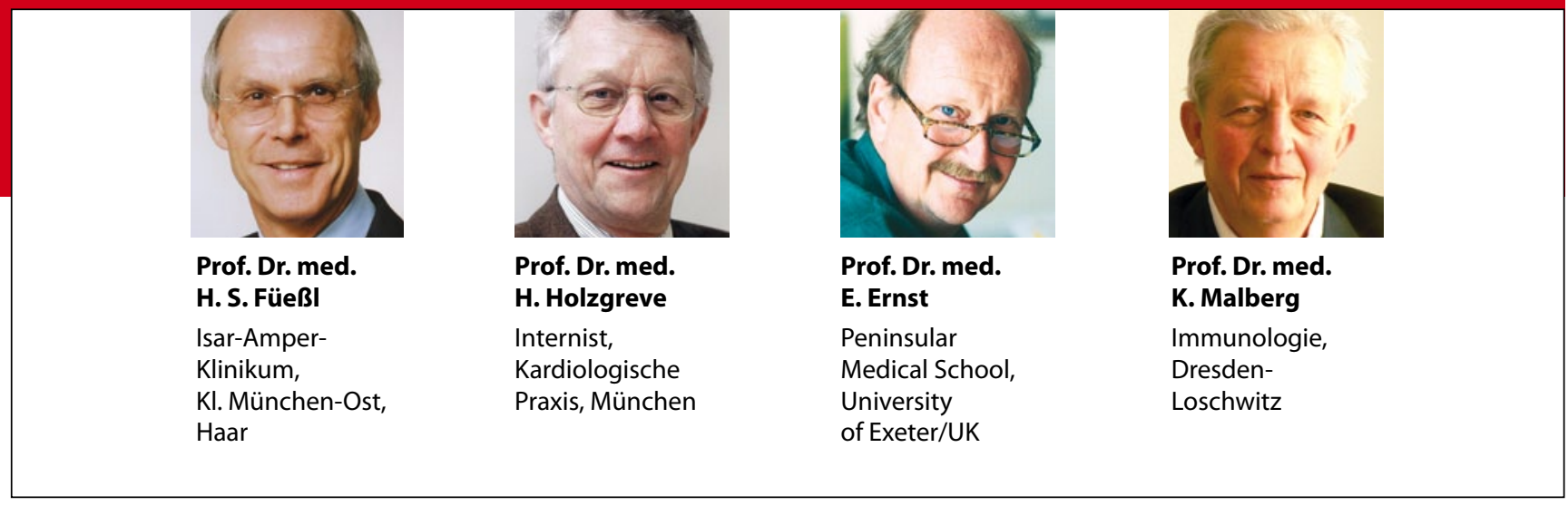

\section{Aktive Dicke leben länger als faule Dünne}

\begin{abstract}
Stark übergewichtige Menschen können länger leben als extrem Schlanke, wenn sie sich nur ein bisschen bewegen. Bewegung lässt Fettleibige im Schnitt länger leben als normalgewichtige und völlig inaktive Menschen. Eine große Studie belegt den positiven Einfluss von Sport auf die Lebenserwartung - egal, ob jemand dick ist oder dünn.
\end{abstract}

- US-Forscher analysierten Daten aus sechs Untersuchungen mit 654827 Teilnehmern im Alter von 21 bis 90 Jahren. Das Team vom Nationalen Krebsinstitut in Bethesda (Georgia, USA) nutzte als Kriterium für Fettleibigkeit den so genannten Body-Mass-Index (BMI), der das Körpergewicht ins Verhältnis zur Körpergröße setzt. Wer einen BMI von 25 oder höher hat, gilt nach der Definition der Weltgesundheitsorganisation WHO als übergewichtig, bei einem BMI ab 30 als fettleibig.

Die Wissenschaftler unterstreichen den positiven Effekt selbst von leichter körperlicher Betätigung. Wer beispielsweise wöchentlich rund 75 Minuten zügig geht, steigert seine Lebenserwartung im Schnitt um 1,8 Jahre [95\%-KI: 1,6$2,0)$. Menschen, die zwar Normalgewicht hatten (BMI 18,5 bis 24,9), sich aber kaum bewegten, starben hingegen im Schnitt 3,1 Jahre früher als aktive Dicke (BMI 30 bis 34,9). Den extremsten Unterschied an Lebensjahren machten die Forscher zwischen inaktiven fettleibigen und regen schlanken Teilnehmern aus: Hier starben die Dicken durchschnittlich 7,2 Jahre früher. Das Team bezog in der Studie nur Todesfälle $a b$ einem Alter von 40 Jahren mit ein.

K. MALBERG =

\section{- S. C. Moore et al.}

(Division of Cancer Epidemiology and Genetics, National Cancer Institute, Bethesda, Maryland, USA; E-mail: moorest@mail.nih.gov) Large pooled cohort analysis. Published online on 06 Nov 2012 in PLoS Med 9(11): e1001335. doi:10.1371/journal.pmed.1001335

\section{Kommentar}

Bewegung hilft, selbst wenn man dabei nicht abnimmt. Diese Ergebnisse könnten helfen, derzeit inaktive Menschen zu überzeugen, dass schon mäßige körperliche Aktivität sich positiv auf die Gesundheit auswirken kann sogar, wenn diese nicht zum Gewichtsverlust führt. Dazu zählen regelmäßige Gartenarbeit und zügiges Spazierengehen. Die sitzende Lebensweise ist ein echter Risikofaktor. Inaktivität ist mittlerweile ein großes Problem rund um den Globus. Laut aktuellen WHOZahlen haben wir pro Jahr 3,2 Millionen Tote durch körperliche Inaktivität. 